\title{
TTF

\section{Stress test specific to tennis (Test): Case study of an elite player}

\author{
Cyril Brechbuhl (FRA), Olivier Girard (FRA), Grégoire Millet(FRA) and Laurent Schmitt \\ (FRA) \\ ITF Coaching and Sport Science Review 2016; 70 (24): 27 - 30
}

\begin{abstract}
Although assessment of the technical, physical and physiological qualities required for performance optimisation is complex in tennis, it is nonetheless essential to training planning. While physical goals are often dissociated from technical ones, we argue that a recently validated stress test specific to tennis, known as "TEST" (Brechbuhl, Girard, Millet, \& Schmitt, 2016), allows to combine both effectively. Differences in forehand and backhand efficiency may occur as a result of fatigue under standardised conditions, thus minimising emotional and tactical effects. The aim of the present case study is to offer a practical reading of TEST in an elite player.
\end{abstract}

Key words: Incremental test, ball hitting, ball speed, training Received: 30 September 2016 Accepted: 10 October 2016 Corresponding author: Cyril Brechbuhl

Email: Cyril.brechbuhl@fft.fr

\section{INTRODUCTION}

Technological and scientific advances have made it possible to gradually progress towards field testing that is more specific and closer to performance specificities. Two aspects seem to favour specific tests (on the court, using real or simulated ballhitting action) over semi-specific tests (close to the activity pattern in terms of work and recovery times) ("Yo-Yo IR2" [Bangsbo, laia, \& Krustrup, 2008]; "30-15 Intermittent Fitness Test" [Buchheit, 2008]; "Shuttle Run Test" [Leger \& Lambert, 1982]): (1) the use of the tennis court dimensions, and (2) the combination of specific footwork and upper body movements (i.e. simulating or executing strokes).

In regards to specific tests, some authors have used tennisspecific movements, but with no actual hitting of the ball (Ferrauti, Kinner, \& Fernandez-Fernandez, 2011; Girard, Chevalier, Leveque, Micallef, \& Millet, 2006), while others have integrated real ball-hitting action with assessment of hitting accuracy (Baiget, Fernandez-Fernandez, Iglesias, Vallejo, \& Rodriguez, 2014; Davey, Thorpe, \& Williams, 2002; Smekal et al., 2000) or without any technical assessment (Fargeas-Gluck $\&$ Leger, 2012). There is a growing desire to relate parameters of technical performance (stroke accuracy and/or velocity) to physiological changes (blood lactate concentration [la], heart rate (HR), oxygen uptake (VO2)) under standardised conditions (Davey et al., 2002; Smekal et al., 2000; Vergauwen, Spaepen, Lefevre, \& Hespel, 1998).

By comparing physiological responses between a field-based procedure and a discontinuous treadmill test, Girard et al. (2006) highlighted that laboratory tests underestimate maximal oxygen uptake (VO2max) values, while the main cardiorespiratory variables (HR, VO2) measured at submaximal intensities did not differ (Girard et al., 2006). We prefer tests that integrate real ball-hitting action because upper body contribution, which has a significant influence on energy expenditure as reported in the literature (FernandezFernandez, Kinner, \& Ferrauti, 2010), must be taken into account. To date, no comparison of physiological influences between simulated and actual strokes (without distinguishing forehand and backhand strokes) has been published in the literature.
From a study case, we will see how TEST (Brechbuhl, Girard, Millet, \& Schmitt, 2016) allows to have a physiological approach while ensuring that technical execution meets the requirements of high performance.

\section{EQUIPMENT AND METHOD}

Player

The subject is an elite male player, aged 19 at the time of the test. After having been one of the most promising junior players, he continued to perform well on the tour, reaching second weeks of Grand Slams and winning ATP titles.

Article received: 30 September 2016 Article accepted: 10 October

2016

A

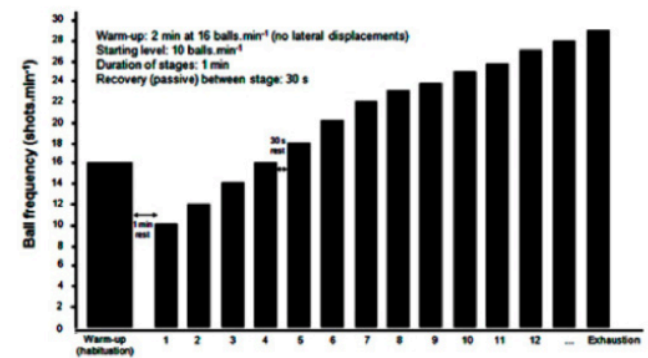

B

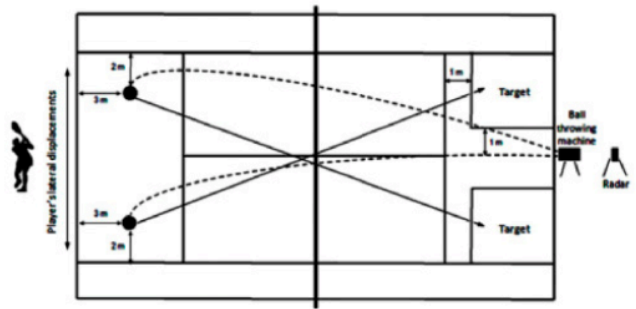

Figure 1 - TEST design (A) and schematic setting (B) (Brechbuhl, Girard, et al., 2016). GAS ANALYSIS SYSTEM

Test Protocol

TEST procedure consists of hitting balls thrown at a mean velocity of $86 \mathrm{~km} . \mathrm{h}-1$ by a Hightof' ball machine, alternating crosscourt forehand and backhand strokes (Brechbuhl, Millet, 
\& Schmitt, 2016) (Figure 1). After a 2-minute "habituation" phase (ball frequency of 16 shots.min-1), the first stage consists of a ball frequency of 10 shots.min-1, which is then increased by 2 shots.min-1 every minute until the stage corresponding to 22 shots.min-1 is reached. From there, increment in ball frequency is set at +1 shot.min-1 until exhaustion. Between each stage, a 30-second (passive) recovery break is implemented. TEST allows a simultaneous evaluation of physiological and technical variables. Ball velocity (using a radar) and accuracy values are recorded for each stage completed. Player is encouraged to find the right balance between ball speed and accuracy. Combined, velocity and accuracy parameters give an insight on technical performance (PerfTennis) (Figure 3B).

We chose the Cortex MetaMax $3 \mathrm{~B} \otimes$ analyser because of its ease of use, light weight and compact size. It weighs 570 grams and allows to measure $\mathrm{HR}, \mathrm{VO}$, carbon dioxide production (VCO2) and ventilation (VE). Ventilatory threshold (VT1 and VT2) detection was done by analysing the points of change in slope (breaks in linearity) of ventilatory parameters (Wasserman, 2005).

Furthermore, for the player's optimal comfort, we used a neoprene mask which does not obstruct vision. In order to hold the MetaMax $3 \mathrm{~B} \otimes$ system in place during the player's movements, we used a breathable, comfortable Surgifix elastic net bandage (Picture 1 ).

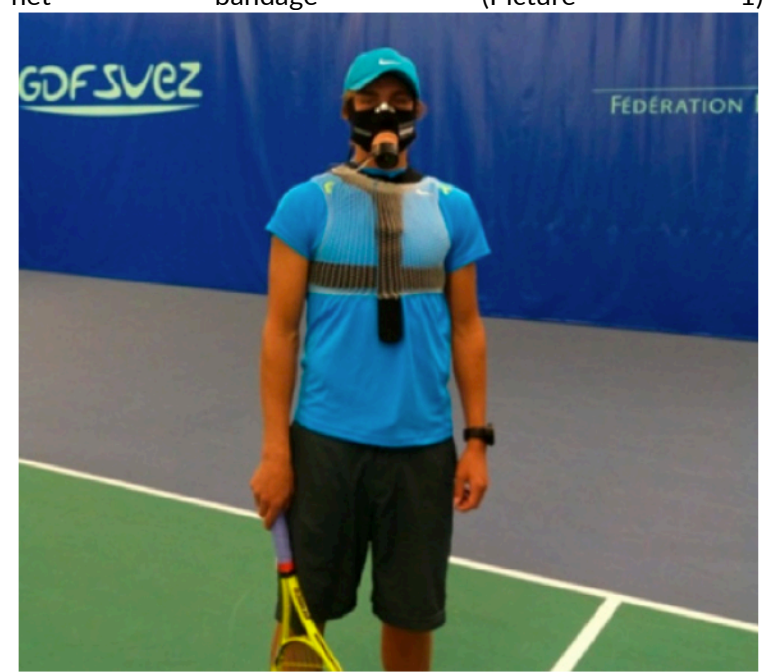

LACTATE CONCENTRATION MEASUREMENT

Capillary blood samples were taken from fingertip and analysed for lactate concentrations as per current guidelines (Dassonville et al., 1998). Samples were taken on the nondominant hand to preserve the quality of the player's racket grip. Accordingly, during TEST, measurement was done every two stages using the Lactate Pro II analyser by Arkray ${ }^{\circledR}$.

BALL VELOCITY AND ACCURACY MEASUREMENT

Groundstroke efficiency was determined from ball velocity (km.h- 1) measured using the Solstice 2 radar (Hightof' $($, France), and accuracy measured by a coach who recorded data on a touch screen. Groundstroke accuracy value was derived from the percentage (\%) of balls landing in the target zone defined in Figure 1.

RESULTS

Data on physiology and technical performance relative to increasing effort are shown in tables and figures below.
Zone 1: Pure aerobic zone, below LT1 (first lactate threshold) and VT1 (first ventilatory threshold).

\begin{tabular}{|c|c|c|c|c|c|c|c|}
\hline $\begin{array}{c}\text { Zume } \\
\text { d'intensité }\end{array}$ & Palter & $\mathrm{n}$ balles $\min ^{-1}$ & $\begin{array}{c}\mathrm{FC} \\
(\mathrm{bpm})\end{array}$ & $\begin{array}{c}\text { Lactates } \\
\text { (mnoi.i') }\end{array}$ & $\begin{array}{c}\mathrm{VO} 2 \\
\left.\text { (ml.nin }{ }^{-1} \cdot \mathrm{kg}^{-1}\right)\end{array}$ & $\underset{\left(\mathrm{ml} . \mathrm{min}^{-1} . \mathrm{kg}^{-1}\right)}{\mathrm{VCO}}$ & $\begin{array}{c}\mathrm{VE} \\
\left(\operatorname{l.min}^{-1}\right)\end{array}$ \\
\hline \multirow{6}{*}{ zane 1} & 1 & 111 & 131 & & 40.2 & 366 & $6 x$ \\
\hline & 2 & 12 & 140 & 1 & 41.5 & 39.0 & 74 \\
\hline & 3 & 14 & 154 & & 43.9 & 42.7 & 79 \\
\hline & 4 & 16 & 159 & 1.2 & 45.1 & 45.7 & 84 \\
\hline & 5 & 18 & 165 & & 47.6 & 48.8 & 87 \\
\hline & 6 & 20 & 171 & 1.4 & 50.4 & 51.2 & 95 \\
\hline \multirow{3}{*}{ Yane 2} & 7 & 22 & 175 & & 53.2 & 53.3 & 98 \\
\hline & $x$ & 23 & $1 \times 0$ & 2.1 & 55.6 & 571 & 104 \\
\hline & 9 & 24 & 183 & & 57.4 & 61.2 & 115 \\
\hline \multirow{3}{*}{ Zone 3} & 10 & 25 & 184 & 4.2 & 59.6 & 65.2 & 125 \\
\hline & 11 & 26 & 188 & & 60.5 & 68.1 & 133 \\
\hline & 12 & 27 & 189 & & 61.5 & 70.2 & 145 \\
\hline
\end{tabular}

Table 1 - Physiological responses during the completion of TEST in an elite player. HR: heart rate; VO2: oxygen uptake; VCO2: carbon dioxide production; VE: ventilation. Height: $185 \mathrm{~cm}$; Weight: $82 \mathrm{~kg}$.

Aerobic endurance training: increased vascularisation of muscles, increase in the number and size of mitochondria, increase in the amount of aerobic enzymes (Krebs cycle) and beta-oxidation enzymes.

Zone 2: Zone between the first and second lactate thresholds (or below VT2); zone of aerobic development through increased use of shuttle systems of transport of hydrogen ions (NADH2); mixed zone of lipid and carbohydrate use.

Zone 3: Above the second lactate threshold and VT2; zone of elevated blood lactate levels; decrease in tennis performance level as a result of muscle acidosis and hyperventilation. Maximal aerobic power training. Increased cardiopulmonary capacity, increased transport of oxygen, increased glycolytic enzymes (PFK and LDH during conversion of lactate into pyruvate), improved muscle buffering capacity, increased muscle glycogen stores.

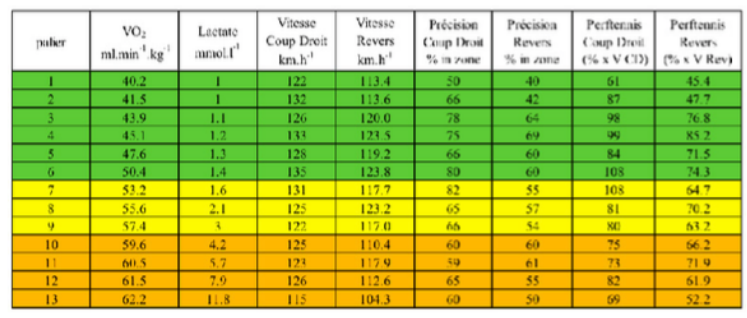

Table 2 - Parameters of technical performance as measured during TEST in an elite player.

DISCUSSION

The growth of training methodologies in tennis forces us to think about ways to optimise time and resources used. How can we make strength training techniques coexist with those designed for the development of speed, endurance and technical skills? Our aim is to suggest an approach which combines physiological capacity development and technical skill training based on data provided by TEST.

A "polarised" approach to training, whereby approximately $75 \%$ of total training volume is performed at low aerobic intensities (Zone 1), and $10-15 \%$ is performed at high or very high intensities (Zone 3), has been suggested as an optimal training intensity distribution for elite athletes who perform intense exercise events (Laursen, 2010). Clearly, such a distribution can hardly be applied to tennis considering the routines and exercises that we typically find in our sport, but this proposal serves as a basis for our discussion. In a recent study on tennis players' energy responses during competition (Baiget, Fernandez-Fernandez, Iglesias, \& Rodriguez, 2015), Baiget et al. (2015) found that players spend $77 \%( \pm 25 \%)$ of playing time in the low intensity zone (Zone 1), 20\% ( $\pm 21 \%)$ in the moderate intensity zone (Zone 2 ), and $3 \%( \pm 5 \%)$ in Zone 3 . TEST data 
allow for this organisation of the workload.
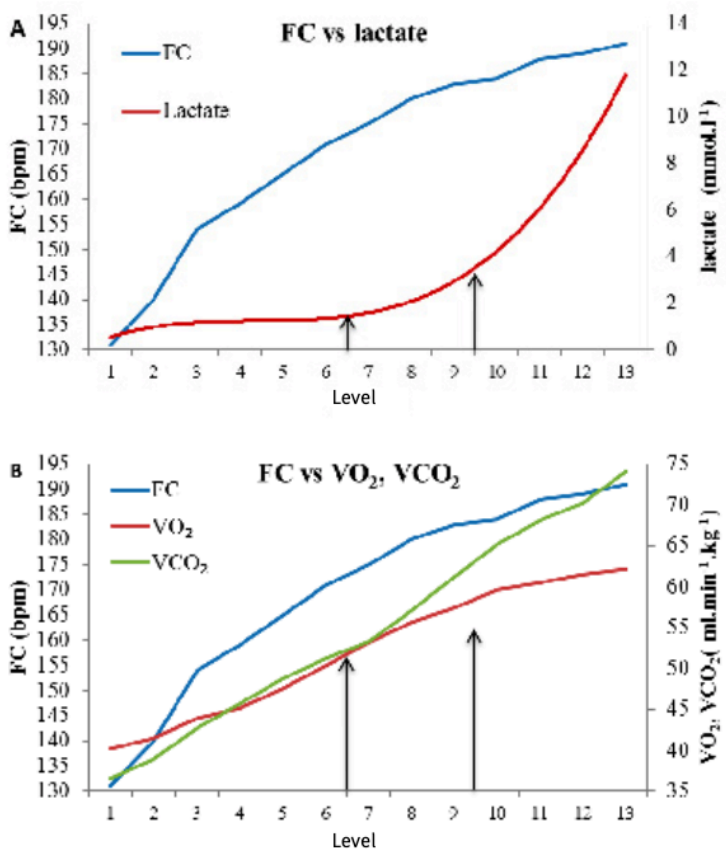

Figures $1 A$ and $1 B$ - Changes in heart rate (HR) in relation to lactate concentration $(A)$ and oxygen uptake $\left(\mathrm{VO}_{2}\right)$ and carbon dioxide production $\left(\mathrm{VCO}_{2}\right)$ (B) during completion of TEST. Vertical arrows indicate $V T_{1}$ and $V T_{2}$.

Training effects on general physiological state must contribute to balancing the influences on athletes' neurovegetative activity (Schmitt et al., 2015). It has become evident that most training situations that incorporate repetitions of ball-hitting drills with a high level of commitment bring players close to VT2 (Reid, Duffield, Dawson, Baker, \& Crespo, 2008). Therefore, we encourage coaches to reconsider predominantly technical training sessions with a focus on a limited number of strokes that does not exceed $7 \mathrm{~s}$, and 20 -s recovery periods between repetitions. This way, glycogen stores - particularly used at such intensity levels - would be preserved and it would allow for repetitions of ball-hitting drills at VT1 (i.e. Stage 6 in the studied case, which corresponds to an intensity level of 20 shots.min-1). Similarly, analysis of activity under competitive conditions (Baiget et al., 2015) supports the assumption that forms of points played with serve should aim to maintain players close to Zone 1 with less deleterious effects on fatigue. From TEST, goals focused primarily on technique (Zones 1 and 2) or energy (Zone 3) can be pursued, with a focus on quality of stroke production and feedback on velocity and accuracy (Table 2). For Zone 1, for example, the goal would be to keep the session going as long as possible at Stage 6, which corresponds to VT1 (i.e. $81 \%$ VO2max or $89 \%$ HRmax for the player in our study), with 2 or 3 series of 5 to 10 minutes of continuous activity and 3-minute passive recovery periods between series. Alternatively, if the goal is Zone 3, shorter hitting intervals ( $15 \mathrm{~s}$ to $1 \mathrm{~min}$ ), interspersed with passive recovery periods (15-30 s), should be preferred. In all cases, it is advisable to avoid falling below a $50 \%$ rate of balls in the defined target zone for expert players; and a $40 \%$ rate for less experienced players (Lyons, Al-Nakeeb, Hankey, \& Nevill, 2013) during TEST. In the present study case, we observed a somewhat stable ball velocity during the test. In contrast, changes in accuracy were quite significant for forehand strokes: first between Stages 4 and 5 (-12\%), and then more noticeably

between Stages 7 and $8(-20 \%)$. In both cases, the player had not yet reached VT2. Therefore, it is important to put the emphasis on forehand accuracy when working at Zones 1-2. It should also be noted that values attained by our player compare favourably with those published elsewhere. Indeed, at the lowest point of the start of the decline, we still observed a $65 \%$ accuracy rate in forehand (Stage 8 ), still $15 \%$ above the average values found by Lyons (Lyons et al., 2013) for expert players, even though our target zones were smaller. Nevertheless, in the interest of progress, a work plan can clearly

be

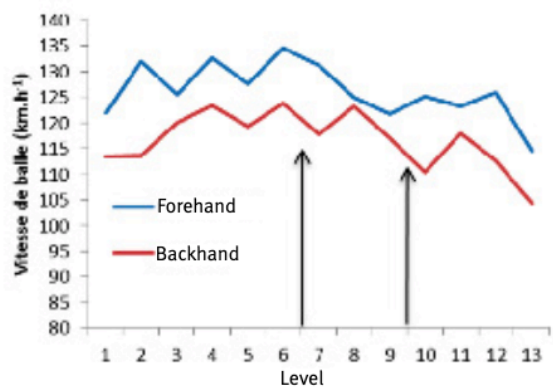

Figure 2 - Forehand and backhand ball velocity during completion of TEST. Vertical arrows indicate VT1 and VT2.
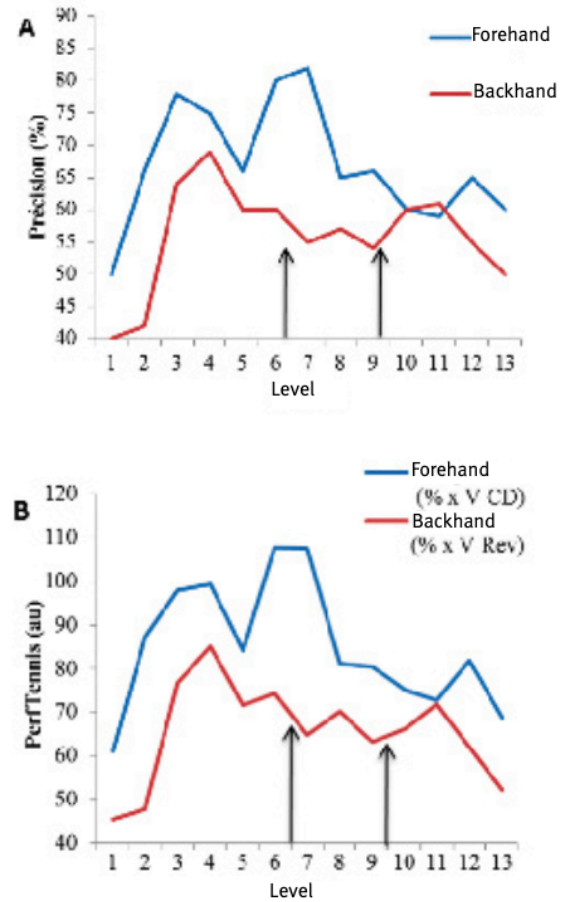

Figure $3 A$ and $3 B-$ Accuracy levels and technical performance (PerfTennis) during TEST.

\section{CONCLUSION}

Considering the complexity of performance and trainable performance factors, training themes in tennis appear to be too frequently treated analytically. Through TEST and its applications, our aim is to suggest a global approach designed to avoid redundant physiological demands. Without 
underestimating the diversity of practices, this approach may contribute to a more efficient planning of training contents and a better management of fatigue.

\section{REFERENCES}

Baiget, E., Fernandez-Fernandez, J., Iglesias, X., \& Rodriguez, F. A. (2015). Tennis Play Intensity Distribution and Relation with Aerobic Fitness in Competitive Players. [Research Support, Non- U.S. Gov't]. PLoS One, 10(6), e0131304. doi: 10.1371/journal. pone.0131304

Baiget, E., Fernandez-Fernandez, J., Iglesias, X., Vallejo, L., \& Rodriguez, F. A. (2014). On-court endurance and performance testing in competitive male tennis players. J Strength Cond Res, 28(1), 256-264. doi: 10.1519/JSC.0b013e3182955dad

Bangsbo, J., laia, F. M., \& Krustrup, P. (2008). The Yo-Yo intermittent recovery test : a useful tool for evaluation of physical performance in intermittent sports. [Research Support, Non-U.S. Gov't Review]. Sports Med, 38(1), 37-51.

Brechbuhl, C., Girard, O., Millet, G. P., \& Schmitt, L. (2016). On the Use of a Test to Exhaustion Specific to Tennis (TEST) with Ball Hitting by Elite Players. PLoS One, 11(4), e0152389. doi: 10.1371/ journal.pone.0152389

Brechbuhl, C., Millet, G., \& Schmitt, L. (2016). Accuracy and Reliability of a New Tennis Ball Machine. J Sports Sci Med, 15(2), 263-267.

Buchheit, M. (2008). The 30-15 intermittent fitness test: accuracy for individualizing interval training of young intermittent sport players. J Strength Cond Res, 22(2), 365-374. doi: 10.1519/ JSC.0b013e3181635b2e

Dassonville, J., Beillot, J., Lessard, Y., Jan, J., Andre, A. M., Le Pourcelet, C., Rochcongar, P., Carre, F. (1998). Blood lactate concentrations during exercise: effect of sampling site and exercise mode. [Clinical Trial]. J Sports Med Phys Fitness, 38(1), 39-46.

Davey, P. R., Thorpe, R. D., \& Williams, C. (2002). Fatigue decreases skilled tennis performance. J Sports Sci, 20(4), 311-318. doi: $10.1080 / 026404102753576080$

Fargeas-Gluck, M. A., \& Leger, L. A. (2012). Comparison of two aerobic field tests in young tennis players. [Comparative Study]. J Strength Cond Res, 26(11), 3036-3042. doi: 10.1519/ JSC.0b013e3182472fc3

Fernandez-Fernandez, J., Kinner, V., \& Ferrauti, A. (2010). The physiological demands of hitting and running in tennis on different surfaces. [Comparative Study Randomized Controlled Trial]. J Strength Cond Res, 24(12), 3255-3264. doi: 10.1519/ JSC.0b013e3181e8745f

Ferrauti, A., Kinner, V., \& Fernandez-Fernandez, J. (2011). The Hit \& Turn Tennis Test: an acoustically controlled endurance test for tennis players. [Research Support, Non-U.S. Gov't Validation Studies]. J Sports Sci, 29(5), 485-494. doi: $10.1080 / 02640414.2010 .539247$

Girard, O., Chevalier, R., Leveque, F., Micallef, J. P., \& Millet, G. P. (2006). Specific incremental field test for aerobic fitness in tennis. [Comparative Study Randomized
Controlled Trial]. Br J Sports Med, 40(9), 791-796. doi: $10.1136 /$ bjsm.2006.027680

Laursen, P. B. (2010). Training for intense exercise performance: high-intensity or high-volume training? [Review]. Scand J Med Sci Sports, 20 Suppl 2, 1-10. doi: 10.1111/j.1600-0838.2010.01184.x

Leger, L. A., \& Lambert, J. (1982). A maximal multistage 20-m shuttle run test to predict VO2 max. [Comparative Study Research Support, Non-U.S. Gov't]. Eur J Appl Physiol Occup Physiol, 49(1), 1-12.

Lyons, M., Al-Nakeeb, Y., Hankey, J., \& Nevill, A. (2013). The effect of moderate and high-intensity fatigue on groundstroke accuracy in expert and non-expert tennis players. J Sports Sci Med, 12(2), 298-308.

Reid, M., Duffield, R., Dawson, B., Baker, J., \& Crespo, M. (2008). Quantification of the physiological and performance characteristics of on-court tennis drills. [Research Support, Non- U.S. Gov't]. Br J Sports Med, 42(2), 146-151; discussion 151. doi: 10.1136/bjsm.2007.036426

Schmitt, L., Regnard, J., Parmentier, A. L., Mauny, F., Mourot, L., Coulmy, N., \& Millet, G. P. (2015). Typology of "Fatigue" by Heart Rate Variability Analysis in Elite Nordic-skiers. Int J Sports Med, 36(12), 999-1007. doi: $10.1055 / \mathrm{s}-0035-1548885$

Smekal, G., Pokan, R., von Duvillard, S. P., Baron, R., Tschan, H., \& Bachl, N. (2000). Comparison of laboratory and "on-court" endurance testing in tennis. [Comparative Study]. Int J Sports Med, 21(4), 242-249. doi: 10.1055/s-2000-310

Vergauwen, L., Spaepen, A. J., Lefevre, J., \& Hespel, P. (1998). Evaluation of stroke performance in tennis. [Research Support, Non-U.S. Gov't]. Med Sci Sports Exerc, 30(8), 1281-1288.

Wasserman, K., Hansen J., SUE DY, Stringer, WW., \& Whipp BJ. (2005). Principles of exercise testing and Interpretation: Including Pathophysiology and Clinical Applications. Philadelphia, PA.

RECOMMENDED ITF TENNIS ACADEMY CONTENT (CLICK BELOW)

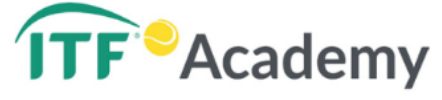

Copyright (c) Cyril Brechbuhl, Olivier Girard, Grégoire Millet and Laurent Schmitt 2016

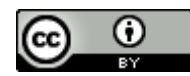

This text is under a Creative Commons BY 4.0 license

You are free to Share - copy and redistribute the material in any medium or format - and Adapt the content - remix, transform, and build upon the material for any purpose, even commercially under the following terms:

Attribution: You must give appropriate credit, provide a link to the license, and indicate if changes were made. You may do so in any reasonable manner, but not in any way that suggests the licensor endorses you or your use.

CC BY 4.0 license terms summary $\quad$ CC BY 4.0 license terms 